\title{
Adoption of Unified Communications and Collaboration from the Perspective of Diffusion of Innovation and Service-Dominant Logic: A Preliminary View
}

\author{
Emy Salfarina Alias", Muriati Mukhtar", Ruzzakiah Jenal ${ }^{\#}$ \\ ${ }^{\#}$ Center for Software Technology and Management, Faculty of Information Science and Technology, \\ Universiti Kebangsaan Malaysia, 43600 Bangi Selangor, Malaysia \\ E-mail:emysalfarina@hotmail.com,muriati@ukm.edu.my,ruzzakiahjenal@ukm.edu.my
}

\begin{abstract}
Unified Communications and Collaboration (UC\&C) is a platform that has become increasingly popular in recent years and used in organizations. The service could increase flexibility, interoperability, efficiency, and productivity in managing business processes. As the number and variety of UC\&C tools and services increases, many organizations have developed strategic plans and allocated budget to implement UC\&C. However, the adoption of some UC\&C tools is still below than expected. As a service that continues to evolve in tandem with new developments in technology, it is thus important to investigate the factors that impact upon the adoption of UC\&C tools and services. Via a review of the literature, this paper will posit an initial model for the adoption of UC\&C. This initial model is developed by adopting the views of two important theories which are the theory of Diffusion of Innovation (DOI) and service-dominant logic (SDL). The DOI theory is chosen since UC\&C represents evolvement in the communications technology space, while SDL is chosen because of its focus on value co-creation and user-centeredness, which is an important factor that will influence adoption. The key factors influencing the adoption of UC\&C embodied in the model will provide useful insights for managers in implementing $\mathrm{UC} \& \mathrm{C}$ in their organizations.
\end{abstract}

Keywords - adoption theory; service science; Diffusion Of Innovation (DOI); Service-Dominant Logic (SDL); Unified Communication And Collaboration (UC\&C).

\section{INTRODUCTION}

The rapid growth of the internet and communications technology (ICT) worldwide has encouraged organizations to migrate towards unified communications and collaboration (UC\&C). UC\&C is the technology which combines traditional communications and computer technology into a platform for more effective communications exchange. UC\&C also can be described as a set of technological innovations that are incorporated into a software package [1]. In addition, the UC\&C services provide the integration of real-time communication services across multiple devices and media types.

In the past few years, UC\&C are becoming popular and are implemented in organizations for optimizing the efficiency of employees. UC\&C has continuously evolved parallel with the improvement in technology. Nowadays more tools are becoming a part of the evolving suite of UC\&C tools. A review of the literature reveals that research in UC\&C can be loosely classified into two broad areas. One is the research concerning the technical or technological aspects of UC\&C which is in abundance. The other stream concerns empirical studies that investigate the adoption of UC\&C. In this aspect, the literature reveals that there is still limited work in this area [2]-[4]. Based on the works of Silic $\&$ Back [5] and several others who investigate the adoption and use of $\mathrm{UC} \& \mathrm{C}$ in organizations in order to understand better the user's decision making process in adopting UC\&C, it can be concluded that there is still much work to be done in the area. Thus this paper will focus on the latter aspect by researching on the factors influencing $\mathrm{UC} \& \mathrm{C}$ adoption in order to ensure that the UC\&C will continue to be relevant and useful for organizations. This paper's contributions will be two-fold. Firstly, the paper will show that the lens through which UC\&C should be viewed through must be the lens of service innovation and secondly based on this view, we will propose a UC\&C adoption model.

\section{MATERIAL AND METHOD}

\section{A. Unified Communications and Collaboration (UC\&C)}

With the growth of technology, communication services have also grown since it was introduced in 1880 , with the 
advent of the telegraph. The evolution of UC\&C has five stages: 1) Separate Communications; 2) Mixed Communications; 3) Unified Communications; 4) Social Communications and Collaboration; 5) Unified Communications and Integrated Collaboration. UC\&C is the integration of software and hardware to provide real-time communication services [6]. The services of UC\&C include voice mail, email, text message, fax, instant messaging, video, and web conferencing [7], [8]. According to Lassman and Pray [9], there are four major phases in the execution of UC\&C initiative: 1) strategize and plan; 2) select and solution; 3) deploy, and 4) operate and evolve.

UC\&C is perceived in various ways by different organizations. The definition of UC\&C in the industry context is specified in the services that are offered by vendors [10]. It focuses more on the business process, product functionalities, and services. From the academic perspective, technically, it highlights on protocol, features, and frameworks [10]. UC\&C is beneficial because it improves message exchange and problem-solving between employees; it increases the efficiency of communication; it helps develop closer relationships with client and partners; it supports recordings of meetings, reduces telephone service costs and also traveling costs [6]. The main sectors that use $\mathrm{UC} \& \mathrm{C}$ are the financial, education, health, manufacturing, banking, public sector, information technology, retail, logistics, pharmaceutical and business sector.

\section{B. Existing Models for the Adoption of $U C \& C$}

This subsection explores the existing models and theories that have been used for understanding, predicting and explaining human behavior in adopting new technologies in particular UC\&C technology. Various researches well research technology acceptance and adoption studies over the years. Among the well-known technology adoption models according to Olushola and Abiola [11] are technology acceptance model (TAM) [12], theory of planned behaviour (TPB) [13], unified theory of acceptance and use of technology (UTAUT) [14], Diffusion of Innovation (DOI) theory [15], and the Technology, Organizations and Environment (TOE) framework [16].

In understanding the issues that lead to or hinder UC\&C adoption, a literature review and analysis was conducted. It is a systematic process that involves searching, selecting, evaluating, and synthesizing documents which were then examined and interpreted for useful information [17]. This document review is carried out to identify the underlying theories and factors that influence the adoption of UC\&C. The details of the review procedure are given in Table I.

TABLE I

The CATEgories Of DOCUMENT REVIEW Procedure

\begin{tabular}{|l|l|}
\hline Categories & Details \\
\hline Keywords & $\begin{array}{l}\text { UC, UC\&C, Technology Adoption Models, } \\
\text { Service-Dominant Logic, Service Science, } \\
\text { UC\&C Adoption, innovation }\end{array}$ \\
\hline Search engines & Google, Google Scholar, \\
\hline Databases & $\begin{array}{l}\text { ISI, Scopus, Science Direct, Jstor and Springer } \\
\text { Link }\end{array}$ \\
\hline $\begin{array}{l}\text { Document } \\
\text { types }\end{array}$ & $\begin{array}{l}\text { Journals, Proceedings, White Papers, Reports, } \\
\text { Theses, and Books. }\end{array}$ \\
\hline
\end{tabular}

A literature search with keyword UC\&C or "united communications and collaboration" using the Google Scholar search engine returned 352 hits concerning various aspects of UC\&C ranging from patents in UC\&C implementation and deployment to UC\&C use and adoption. However, in searching specifically for UC\&C adoption models reveal only 9 relevant sources (see Table 2). These nine studies are then classified based on the underlying theories, frameworks or models used, unit of analysis and method of inquiry. Further analysis for each paper reveals the factors that influence UC\&C adoption for each study. As can be seen in Table 2, influencing factors of adoption and use of UC\&C are varied. Using a quantitative approach, a total of 296 employees from 50 different countries are surveyed by Silic \& Back [5]. It was discovered that use behavior, effort expectancy, facilitating conditions, intention to use, performance expectancy and social influence are factors that influence adoption. In a similar study, Silic \& Back [18] also found out that culture has an impact on technology adoption and use of UC\&C. Bakker [1] discovered that organizational, inter-organizational, technical and economic perspectives are essential drivers of adoption. Other factors are given in detail in Table II.

In summarizing the nine studies on UC\&C adoption, it is important to note the following:

1) No one theory is used throughout by the researchers. Silic \& Back [5], taking inspiration from technology acceptance studies, employed UTAUT as the underlying theory while others used TOE, DOI, or combinations of different perspectives, and even Kairu [22] did not mention any theory used in his research. The unit of analysis also varies. Some studies focus on users' adoption of UC\&C and others focus on organizational adoption. It is also interesting to note that the method used is either the case study approach or the quantitative approach or a mixture of both. The case study approach is used when the researcher is investigating adoption issues in specific companies like General Motors Bolton [2] and Nokia [22] and a small and medium company in Taiwan [6].

2) It is observed that there are common factors, like organizational culture and, user elements (behavior, habits, attitudes, workstyles, user skills and ease of use) that are uncovered by different studies.

There is a dearth of research in UC\&C adoption studies. This state of events is mentioned by Bolton [2]. The leading researcher in the area is Silic and Back [5], [18], [20] a total of three articles. However, UC\&C technologies are continuing to evolve with its cloud implementation in the form of Unified Communication as a Service (UCaaS) [23], and, the importance of unified communications is also underlined by Dery et al. [24] as an initiative in digitizing the workplace in a company's digital innovation exercise. Thus we contend that UC\&C adoption studies are just beginning and is essential to be carried out. 
TABLE II

CLASSIFICATION OF EXISTING RESEARCH ON UC\&C ADOPTION

\begin{tabular}{|c|c|c|c|c|c|}
\hline No. & Authors & Underlying theories & Factors affecting adoption & $\begin{array}{l}\text { Unit of } \\
\text { study }\end{array}$ & $\begin{array}{l}\text { Method of } \\
\text { Inquiry }\end{array}$ \\
\hline \multirow[t]{5}{*}{1.} & \multirow{5}{*}{$\begin{array}{l}\text { Bolton et al. } \\
\text { (2017) [2] }\end{array}$} & \multirow{5}{*}{$\begin{array}{l}\text { Based on IT } \\
\text { adoption: } \\
\text { Technology } \\
\text { Acceptance Model }\end{array}$} & Organizational Culture & \multirow[t]{5}{*}{ User } & \multirow{5}{*}{$\begin{array}{c}\text { Case study } \\
\& \\
\text { Quantitative }\end{array}$} \\
\hline & & & Top management support & & \\
\hline & & & User experience & & \\
\hline & & & Ease of use & & \\
\hline & & & In person training & & \\
\hline \multirow[t]{6}{*}{2.} & \multirow{6}{*}{$\begin{array}{l}\text { Silic \& Back } \\
(2016)[5]\end{array}$} & \multirow[t]{6}{*}{ UTAUT } & Use behaviour & \multirow[t]{6}{*}{ User } & \multirow[t]{6}{*}{ Quantitative } \\
\hline & & & Effort expectancy & & \\
\hline & & & Facilitating conditions & & \\
\hline & & & Intention to use & & \\
\hline & & & Performance expectancy & & \\
\hline & & & Social influence & & \\
\hline \multirow[t]{6}{*}{3.} & \multirow{6}{*}{$\begin{array}{l}\text { Onyango (2014) } \\
{[19]}\end{array}$} & \multirow{6}{*}{$\begin{array}{l}\text { People, Process, and } \\
\text { Technology }\end{array}$} & Planning and Business Needs assessment & \multirow[t]{6}{*}{ Organization } & \multirow{6}{*}{$\begin{array}{c}\text { Qualitative } \\
\text { and } \\
\text { Quantitative }\end{array}$} \\
\hline & & & Architectural and Solution Design & & \\
\hline & & & Implementation and integration & & \\
\hline & & & Adoption and Optimization & & \\
\hline & & & Network Convergence & & \\
\hline & & & Communication Convergence & & \\
\hline \multirow[t]{4}{*}{4.} & \multirow[t]{4}{*}{ Wu \& Wang [6] } & \multirow{4}{*}{$\begin{array}{l}\text { Technology, } \\
\text { Organization, and } \\
\text { Environment }\end{array}$} & Learning and growth & \multirow[t]{4}{*}{ Organization } & \multirow[t]{4}{*}{ Case study } \\
\hline & & & Internal processes & & \\
\hline & & & Customer & & \\
\hline & & & Financial & & \\
\hline \multirow[t]{2}{*}{5.} & \multirow{2}{*}{$\begin{array}{l}\text { Silic \& Back } \\
\text { (2013) [18] }\end{array}$} & \multirow{2}{*}{$\begin{array}{l}\text { Competing Value } \\
\text { Model }\end{array}$} & Rational Culture & User & Quantitative \\
\hline & & & Development Culture & & \\
\hline 6. & Silic \& Back & UTAUT & Use behaviour & User & Quantitative \\
\hline & $(2014)[20]$ & & Effort expectancy & & \\
\hline & & & Facilitating conditions & & \\
\hline & & & Intention to use & & \\
\hline & & & Performance expectancy & & \\
\hline & & & Social influence & & \\
\hline 7. & Bakker (2012) & Diffusion of & Inter-organizational & Organization & Quantitative \\
\hline & & Innovation (DOI) & Organizational & & \\
\hline & & & Technical & & \\
\hline & & & $\begin{array}{l}\text { Economic Perspectives: Perceived burdens and } \\
\text { perceived benefits }\end{array}$ & & \\
\hline 8. & Pinnock (2011) & Institutional and & Pressure: Mimetic, coercive, normative, fashion & Organization & Quantitative \\
\hline & [21] & Technological & Organizational culture & & \\
\hline & & Perspective; & Organizational risks & & \\
\hline & & Management & Perceived internal benefits & & \\
\hline & & Fashion Perspective; & Organisational innovativeness & & \\
\hline & & Efficiency Choice & Technical and cost saving alternatives & & \\
\hline & & Perspective & Attention towards users & & \\
\hline & & & Expected usefulness and ease of use & & \\
\hline 9. & Kairu, A (2013) & Not mentioned & Standardization & User & Case study \\
\hline & [22] & & Costs & & $\&$ \\
\hline & & & Complexity and user skills & & Quantitative \\
\hline & & & Security considerations & & \\
\hline & & & User habits, attitudes and work styles & & \\
\hline
\end{tabular}

The above summary of the literature points out to a need for a further investigation into UC\&C adoption. In line with previous researches, it is hypothesized that this further investigation should be based on the identification of an appropriate theory or theories. In this aspect, our guiding principles (in choosing the appropriate theory) are based on two main characteristics of UC\&C. The first is that it is innovative. This can be seen from the fact that it is continuing to evolve from the telegraph in the 1880 s to a cloud-based service in the form of UCaaS. Thus, in agreement with Bakker [1] the diffusion of innovation
(DOI) theory which describes the process flow for guiding the intention of users in adopting new technologies can be used as a basis for discussions on UC\&C adoption. The other is the role of the users in the adoption process. As highlighted by 2) above, user elements are essential and central to the success of adoption. In light of the issues which concerns the users and the use of UC\&C, it is understood that the service-dominant logic Vargo \& Lusch [25] with its focus on value in use will prove valuable as a guiding theory in investigating the users' elements and roles in the adoption of UC\&C. In a recent study by [26] 
and [27] have asserted that SDL theory gives preference to users in determining usage and viewing the value based on the value in use. Thus it is suggested that both servicedominant logic and DOI are used as a lens through which we view UC\&C adoption.

In subsequent sections, a review of both DOI and Service Dominant Logic will be given.

\section{Diffusion of Innovation (DOI)}

Particular community groups adopt innovative technology through the process of diffusion. Rogers [15], via the Diffusion of Innovation (DOI) theory, pointed out that the spread of an innovation is governed by the following four factors (see Fig. 1): (1) the innovation itself which is an idea, object, or practice that is perceived as something new by individuals or units of adoption, (2) the communication channels by which the information on the innovation is spreading, (3) time, which is the rate of the diffusion of innovation or the relative speed with which members or units of adoption adopt it and, (4) the social system, which consists of individuals, organizations, or agencies sharing the same culture and potential adopters of the innovations.

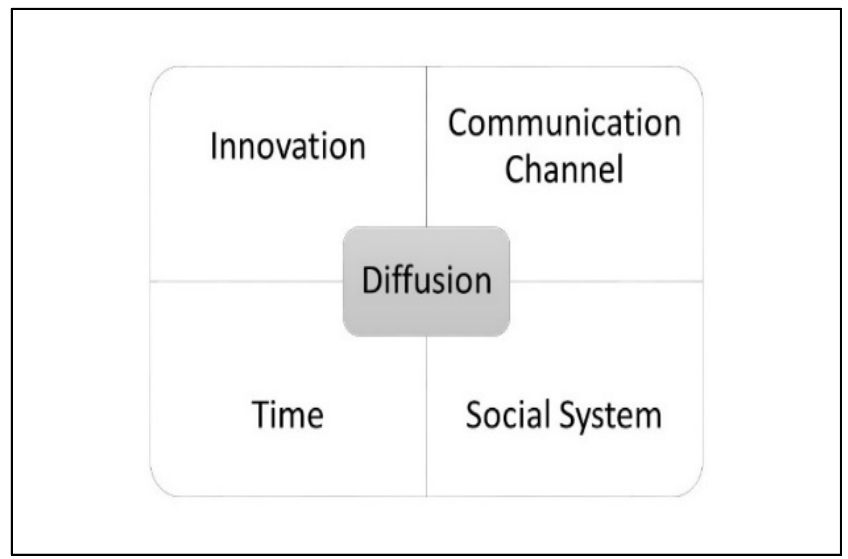

Fig. 1 Four factors that govern the diffusion of innovation [15]

It is logical to assume that the adoption of innovations is contingent upon the adoption of the innovation at the individual level. Rogers [15] underlines five phases of an individuals' adoption process. The five phases are knowledge, persuasion, decision, implementation, and confirmation. In the knowledge phase, individuals are vulnerable to innovation. At this stage, individual features have the most substantial influence. At the persuasion phase, an individual will form a negative or positive perception of the new technology. The third phase of the innovation-decision process, individuals will decide to take or reject the new technological innovations. The next phase, which is the implementation phase, is when the individual uses the innovation. Finally, at the confirmation phase, occurs when the individual has decided to adopt or reject innovation. This process of innovation is illustrated in Table III.
TABLE III

INNOVATION-DECISION PROCESS PHASES.

\begin{tabular}{|l|l|}
\hline Phase & Individual's actions or roles \\
\hline Knowledge & $\begin{array}{l}\text { Occurs when an individual learns about the } \\
\text { existence of the new technology and a clear } \\
\text { understanding of how it works. }\end{array}$ \\
\hline Persuasion & $\begin{array}{l}\text { Occurs when an individual becomes } \\
\text { interested in trying the new technology. }\end{array}$ \\
\hline Decision & $\begin{array}{l}\text { Occurs when an individual is involved in the } \\
\text { activities that lead them to accept or reject the } \\
\text { innovation. }\end{array}$ \\
\hline Implementation & $\begin{array}{l}\text { Occurs when an individual begins to use the } \\
\text { new technology. }\end{array}$ \\
\hline Confirmation & $\begin{array}{l}\text { Occurs when an individual evaluates the } \\
\text { results of an innovation; finalizes the decision } \\
\text { to continue or discontinue using the new } \\
\text { technology. }\end{array}$ \\
\hline
\end{tabular}

Rogers [15] to explain why some innovations are successful, while others never become widely accepted. For an innovation to be successful, an innovation should have five distinct characteristics which are observability, relative advantage, compatibility, trialability, and complexity as follows [1], [15] :

1) Compatibility: The extent to which new technology is perceived as consistent with the existing value, past experiences, and needs of potential individual adopters to be absorbed into the life of adopters.

2) Complexity: The extent to which an innovation is perceived as relatively difficult to understand and use. The complexity of using the new technology will obstruct user to adopt it.

3) Trialability: The extent to which an innovation may be experimented with. The difficulty of using and trying on the innovation will be hampered user to adopt it.

4) Observability: The extent to which the results of an innovation are visible to others. The visibility of innovation will influence communication among the individual's peers and personal networks and will, in turn, generate more positive or negative responses.

5) Relative Advantage: The extent to which an innovation is perceived as being better than the idea it replaces.

The relationship between these factors and adoption is given in Fig. 2.

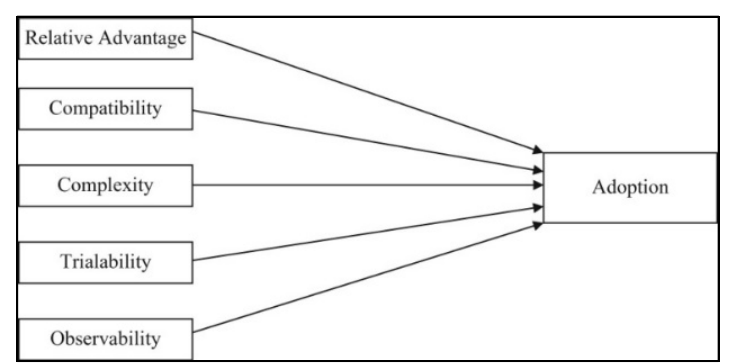

Fig. 2 Diffusion of Innovation Model [15] 


\section{Service Science and Service Dominant Logic}

Traditionally, services are differentiated from goods by contrasting the tangible characteristics of goods with the intangible characteristics of services. Classic examples of services include everything from banking, healthcare, and, logistics to hospitality, entertainment and more. Service science as a domain was introduced in 2004, by IBM [28]. It is a transdisciplinary area which was initially named service science, management, engineering, and design but was later shortened to or service science. In service science, service is defined as the application of specialized competencies (knowledge and skills) through deeds, processes, and performances for the benefit of another entity or the entity itself [29]. Vargo and Lusch [25], [30] provided the area of service science with a theoretical underpinning by the formulation of service-dominant logic. Service-dominant logic (SDL) is a logic which builds on eleven foundational premises (FPs) has been shown in Table IV. Under this logic, service is always the fundamental basis of exchange. The dominant service logic also removes the dichotomy between goods and service. In this logic, goods are just vehicles or mediums for service provision. In the foundational premises, the word service in its singular form is defined as the application of resources and competencies for the benefit of others. This means that service includes all economic activities in which individuals, organizations, and technologies work together, applying specific competencies and capabilities in order to create the most value together [31], [32]. Under this new notion, service is not something that is proposed by an organization to be consumed by its customers, it is, however, something that is co-created by all parties involved to achieve something of value. It is this notion of value co-creation that is central to the adoption of any technology, in this case, UC\&C. We conjecture that the inability for the user to co-create value by using the tools in $\mathrm{UC} \& \mathrm{C}$ will hamper its adoption. Thus it is pertinent that the relevant foundational premises in the dominant service logic are taken into account in determining the factors that impact upon UC\&C adoption. In identifying the relevant foundational premises, we mapped each of the premises to UC\&C by articulating the implications from the FPs on UC\&C adoption. This mapping is given in Table IV.

TABLE IV

THE FOUNDATIONAL PREMISES AND ITS IMPLICATIONS FOR UC\&C ADOPTION

\begin{tabular}{|c|c|c|c|}
\hline FPs & Specification & $\begin{array}{l}\text { Implications in the context of } \\
\text { UC\&C use }\end{array}$ & Interpreted as Adoption factors \\
\hline FP1 & $\begin{array}{l}\text { Service is the fundamental basis } \\
\text { of exchange. }\end{array}$ & $\begin{array}{l}\text { In utilizing UC\&C tools, the } \\
\text { actors involved will be able to } \\
\text { provide a new service for others } \\
\text { or will provide service to } \\
\text { themselves in the form of } \\
\text { improved work performance. }\end{array}$ & \multirow[t]{2}{*}{$\begin{array}{l}\text { Improved service: The degree to which } \\
\text { service is improved or a new service is } \\
\text { created from the introduced innovation. }\end{array}$} \\
\hline FP3 & 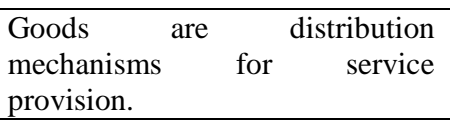 & $\begin{array}{l}\text { UC\&C suite of tools serves as } \\
\text { distribution mechanisms for } \\
\text { service provision. }\end{array}$ & \\
\hline FP6 & $\begin{array}{l}\text { Value is co-created by multiple } \\
\text { actors, always including the } \\
\text { beneficiary. }\end{array}$ & $\begin{array}{l}\text { The value UC\&C is co-created by } \\
\text { all actors involved. }\end{array}$ & $\begin{array}{l}\text { Value co-creation capacity: The degree to } \\
\text { which value co-creation is enabled or } \\
\text { allowed in the organizations. }\end{array}$ \\
\hline FP7 & $\begin{array}{l}\text { Actors cannot deliver value but } \\
\text { can participate in the creation and } \\
\text { offering of value propositions. }\end{array}$ & $\begin{array}{l}\text { Actors cannot deliver the value of } \\
\text { UC\&C tools; they can only offer } \\
\text { value propositions. }\end{array}$ & \multirow{3}{*}{$\begin{array}{l}\text { Efficient resource integration: The degree } \\
\text { of efficiency of the user in integrating all } \\
\text { resources to extract value in use and realize } \\
\text { the benefit from the innovation. }\end{array}$} \\
\hline FP9 & $\begin{array}{l}\text { All social and economic actors } \\
\text { are resource integrators. }\end{array}$ & $\begin{array}{l}\text { In extracting the value from } \\
\text { UC\&C use, all those involved } \\
\text { must integrate all available } \\
\text { resources (operand and operant). }\end{array}$ & \\
\hline FP10 & $\begin{array}{l}\text { Value is always uniquely and } \\
\text { phenomenologically determined } \\
\text { by the beneficiary. }\end{array}$ & $\begin{array}{l}\text { The value UC\&C is the } \\
\text { determined by those that benefit } \\
\text { from them. }\end{array}$ & \\
\hline FP11 & $\begin{array}{l}\text { Value co-creation is coordinated } \\
\text { through actor-generated } \\
\text { institutions and institutional } \\
\text { arrangements. }\end{array}$ & $\begin{array}{l}\text { The process of value co-creation } \\
\text { in UC\&C is coordinated via some } \\
\text { institutional arrangements like } \\
\text { policies. }\end{array}$ & $\begin{array}{l}\text { Coordination Efficiency: The degree to } \\
\text { which the institutions or institutional } \\
\text { arrangements coordinates value co-creation } \\
\text { in the organizations. }\end{array}$ \\
\hline
\end{tabular}

\section{RESULTS AND DISCUSSION}

The journey that resulted in the proposal of the SDL based UC\&C adoption model is best captured in Fig. 3. It started with the literature review on UC\&C adoption models which was elaborated in the materials and methods section. From the literature review, it was found a lack of empirical studies in the UC\&C service; there is a need for further investigation to ensure the service is positively adopted. Considering the UC\&C service is evolving technology, DOI has been selected as the leading theory of the proposed model. User perspective is a preference in adopting new technology. Accordingly, SDL has been infused DOI factors. These two guiding theories are refined and synthesized to identify the elements which affect the adoption of UC\&C services. 


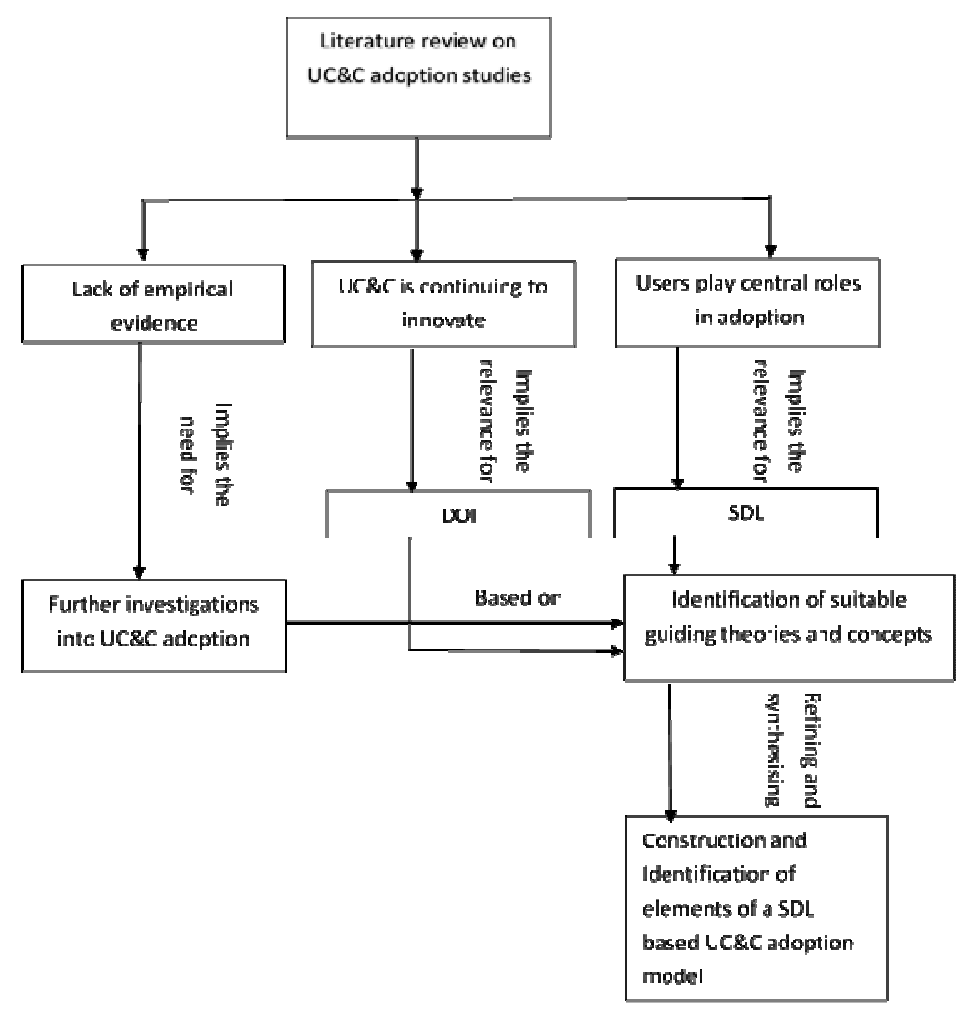

Fig. 3 Process for the development of the proposed model

In proposing the UC\&C adoption model, our approach is to look at the elements proposed in the DOI model (see the elements in Fig. 2) and the elements extracted from service-dominant logic (see the last column in Table IV).
Infusing the concepts of service science into the DOI factors resulted in an SDL based definition of the elements given in bold texts in Table $\mathrm{V}$.

TABLE V

SDL INFUSED DOI FACTORS AND ITS DEFINITIONS

\begin{tabular}{|c|c|c|c|}
\hline DOI factors & Definition & SD concept & SD infused DOI factors \\
\hline Relative advantage & $\begin{array}{l}\text { The extent to which an innovation is } \\
\text { perceived as being better than the idea } \\
\text { it replaces. }\end{array}$ & Proposed value & $\begin{array}{l}\text { Relative Value: The degree to which the } \\
\text { proposed value of the innovation is } \\
\text { perceived to have improved. }\end{array}$ \\
\hline Compatibility & $\begin{array}{l}\text { The extent to which new technology is } \\
\text { perceived as consistent with the existing } \\
\text { value, past experiences, and needs of } \\
\text { potential individual adopters to be absorbed } \\
\text { into the life of adopters. }\end{array}$ & Value in use & $\begin{array}{l}\text { Consistency: The degree to which the } \\
\text { value in use of the innovation is consistent } \\
\text { with the existing values of the adopter. }\end{array}$ \\
\hline Complexity & $\begin{array}{l}\text { The extent to which an innovation is } \\
\text { perceived as relatively difficult to } \\
\text { understand and use. The complexity of } \\
\text { using the new technology will obstruct user } \\
\text { to adopt it. }\end{array}$ & $\begin{array}{l}\text { Integration of } \\
\text { resources }\end{array}$ & $\begin{array}{l}\text { Integrability of resources: The degree to } \\
\text { which the user can integrate all resources } \\
\text { in order to extract value in use of the } \\
\text { innovation. }\end{array}$ \\
\hline Trialability & $\begin{array}{l}\text { The extent to which an innovation may be } \\
\text { experimented with. The difficulty of using } \\
\text { and trying on the innovation will be } \\
\text { hampered user to adopt it. }\end{array}$ & Operant resource & $\begin{array}{l}\text { Experimentality: The degree to which the } \\
\text { operant resource of the user has increased } \\
\text { after trying or experimenting (with) the } \\
\text { innovation. }\end{array}$ \\
\hline Observability & $\begin{array}{l}\text { The extent to which the results of an } \\
\text { innovation are visible to others. The } \\
\text { visibility of innovation will influence } \\
\text { communication among the individual's } \\
\text { peers and personal networks and will in } \\
\text { turn generate more positive or negative } \\
\text { responses. }\end{array}$ & service & $\begin{array}{l}\text { Service experience: The degree to which } \\
\text { the resulting service from the innovation is } \\
\text { seen or experienced by the all in the } \\
\text { network of users. }\end{array}$ \\
\hline
\end{tabular}


It is observed that the definition of "Integrability of resources" given in Table V above is very similar to the definition of "resource integration efficiency" in Table IV. It is decided to use the new element, "resource integration efficiency" in our proposed SDL based UC\&C adoption model. Therefore, this research proposes a model to understand the adoption of UC\&C in organization better.
Individually, the relevant elements of the model are a relative value, consistency, resources integration efficiency, experimentality, service experience, improved service, value co-creation capacity, coordination efficiency. Hence the resulting elements of the proposed SDL based diffusion of innovation model are as for Table VI.

TABLE VI

FACTORS IN SDL BASED UC\&C ADOPTION MODEL

\begin{tabular}{|c|c|c|}
\hline No. & Element & Definition \\
\hline 1. & Relative Value & $\begin{array}{l}\text { The degree to which the proposed value of the innovation is perceived to have } \\
\text { improved. }\end{array}$ \\
\hline 2. & Consistency & $\begin{array}{l}\text { The degree to which the value in use of the innovation is consistent with the } \\
\text { existing values of the adopter. }\end{array}$ \\
\hline 3. & Resource Integration Efficiency & $\begin{array}{l}\text { The degree to which the user can integrate all resources in order to extract value in } \\
\text { use of the innovation. }\end{array}$ \\
\hline 4. & Experimentality & $\begin{array}{l}\text { The degree to which the operant resource of the user has increased after trying the } \\
\text { innovation. }\end{array}$ \\
\hline 5. & Service Experience & $\begin{array}{l}\text { The degree to which the resulting service from the innovation is seen or } \\
\text { experienced by the all in the network of users. }\end{array}$ \\
\hline 6 & Improved Service & $\begin{array}{l}\text { The degree to which service is improved or a new service is created from the } \\
\text { introduced innovation. }\end{array}$ \\
\hline 7. & Value Co-created Capacity & The degree to which value co-creation is enabled or allowed in the organizations. \\
\hline 8. & Coordination Efficiency & $\begin{array}{l}\text { The degree to which the institutions or institutional arrangements coordinates value } \\
\text { co-creation in the organizations. }\end{array}$ \\
\hline
\end{tabular}

The proposed model of this study is constructed as shown in Fig. 4. The proposed model consists of eight constructs that are extracted from the literature and the supporting theories. The researcher has been considered all five of the innovation characteristic from DOI theory, three factors from the SDL theory and security in developing new adoption model for UC\&C. The eight constructs could be expected to influent the adoption of the $\mathrm{UC} \& \mathrm{C}$ services.

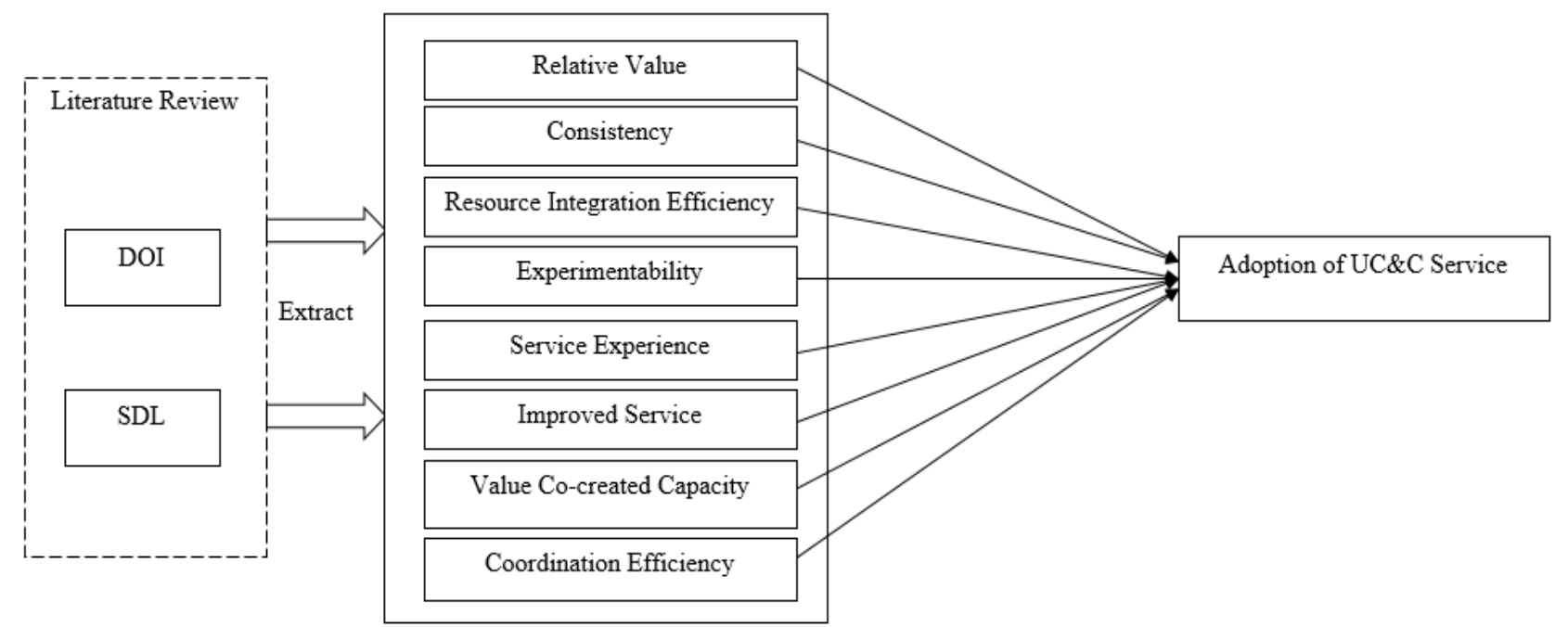

Fig. 4 SDL Based UC\&C Adoption Model

The combination of these two theories will have an impact on the user's perception of the UC\&C adoption.

Therefore, the hypotheses of this study are:

H1: The improvement of the relative value of UC\&C positively influences on the adoption of UC\&C.
$\mathrm{H} 2$ : The value in use of $\mathrm{UC} \& \mathrm{C}$ is consistent positively influences on the adoption of UC\&C.

H3: A user has perceived resource integration efficiency of the UC\&C positively influences the adoption of UC\&C. 
H4: Experimentality on the UC\&C can increase operant resource of the user positively influences on the adoption of UC\&C.

H5: Service Experience can be felt by all in the network of users positively influences the adoption of UC\&C.

H6: Improved Service from the introduced UC\&C positively influences the adoption of UC\&C.

H7: Value Co-created Capacity are allowed in the organization positively influences the adoption of $\mathrm{UC} \& \mathrm{C}$.

H8: Coordination Efficiency in the organization positively influences the adoption of UC\&C.

\section{CONCLUSIONS}

In this article, a case for the development of a UC\&C adoption model is put forward. The proposed model has its roots in the DOI theory and the SDL. We have articulated the reasons for choosing to combine these two theories and shown that by infusing the concepts from the dominant service logic and that of DOI, we can determine eight factors that will have an impact on the adoption of UC\&C. It is acknowledged that the deliberations in this paper are conceptual and has to be further validated by a panel of experts. This paper ends with the eight statements of hypotheses that will be tested in the next step of the research.

\section{ACKNOWLEDGMENT}

The author would like to thank the National University of Malaysia (UKM) for funding this research under Zamalah Research Scheme and research grant, FRGS/2/2014/ICT01/UKM/02/.

\section{REFERENCES}

[1] G. A. Bakker, "Factors affecting the decision of organizations to adopt Unified Communication \& Collaboration Software," Erasmus University, 2012.

[2] A. Bolton, M. Murray, and J. Fluker, "Transforming the Workplace: Unified Communications \& Collaboration Usage Patterns in a Large Automotive Manufacturer," 50th Hawaii Int. Conf. Syst. Sci., pp. 5470-5479, 2017.

[3] J. Yahaya, M. M. Basir, and A. Deraman, "Unified Communication and Collaboration Model for Virtual Distributed Team Work: A Study in Malaysia," Int. J. Softw. Eng. Its Appl., vol. 9, no. 2, pp. 125-142, 2015.

[4] J. Pérez, M. Murray, J. Fluker, D. Fluker, Z. Bailes, and Z. Bailes, "Connectivity and Continuity: New Fronts in the Platform War," Commun. Assoc. Inf. Syst., vol. 40, 2017.

[5] M. Silic and A. Back, "Factors driving unified communications and collaboration adoption and use in organizations," Meas. Bus. Excell., vol. 20, no. 1, pp. 21-40, Mar. 2016.

[6] M. Wu and Y. Wang, "The Benefits of Using Unified Communications Systems for Smes," Int. J. Electron. Bus. Manag., vol. 12, no. 4, pp. 236-246, 2014.

[7] J. Williams and R. C. LaBrie, "Unified communications as an enabler of workplace redesign," Meas. Bus. Excell., vol. 19, no. 1, pp. 81-91, 2015.

[8] B. Abimbola and Qing Tan, "The Relationship Between Unified Communications and Big Data Analytics," J. Fundam. Appl. Sci., vol. 10 , no. 4 S, pp. 382-385, 2018.
[9] J. Lassman and B. Pray, "Unified Communications and Collaboration Key Initiative Overview," Gartner, 2014.

[10] O. Nyathi, A. Terzoli, and M. Tsietsi, "Unicorn: A unified communication solution for marginalized communities," IEEE Int. Conf. Adapt. Sci. Technol. ICAST, pp. 1-6, 2013.

[11] T. Olushola and J. O. Abiola, "The Efficacy of Technology Acceptance Model : A Review of Applicable Theoretical Models in Information Technology Researches," J. Res. Bus. Manag., vol. 4, no. 11, pp. 70-83, 2017.

[12] F. Davis, "Perceived Usefulness, Perceived Ease Of Use, And User Acceptance of Information Technology," MIS Q., vol. 13, no. 3, 1989.

[13] I. Ajzen, "The theory of planned behavior," Organ. Behav. Hum. Decis. Process., vol. 50, no. 2, pp. 179-221, 1991.

[14] V. Venkatesh, M. G. Morris, G. B. Davice, and F. D. Davis, "User Acceptance of Information Technology: Toward a Unified View," $M I S Q$, vol. 27, no. 3, pp. 425-478, 2003.

[15] E. M. Rogers, "Diffusion of preventive innovations," Addict. Behav., vol. 27, no. 6, 2003.

[16] L. G. Tornatzky and M. Fleischer, processes of technological innovation. Lexington: Lexington Books, 1990.

[17] G. A. Bowen, Document Analysis as a Qualitative Research Method, vol. 9, no. 3. 2009.

[18] M. Silic and A. Back, "Organizational Culture Impact on Acceptance and Use of Unified Communications \& Collaboration Technology in Organizations," Challenges Impacts Individ. Organ. Soc., no. June 2013, pp. 275-286, 2013.

[19] O. J. Onyango, "A Model for Adoption of Unified Communication and Collaboration in Organizations," Strathmore University, 2014.

[20] M. Silic, A. Back, and T. Sammer, "Employee Acceptance and Use of Unified Communications and Collaboration in a Cross-Cultural Environment," Int. J. e-Collaboration, vol. 2, no. 10, pp. 1-19, 2014.

[21] B. Pinnock, "Environmental and Organisational Drivers Influencing the Adoption of Unified Communications Technology in South Africa," University of Cape Town, 2011.

[22] A. Kairu, "Investing In A Unified Communications System: A Case of Nokia Siemens Networks In Kenya," United States International University, 2013.

[23] A. D. Tesfamicael, V. Liu, and W. Caelli, "Design, Implementation, and Evaluation of Unified Communications onpremises and over the Cloud," Int. J. Web Sci. Eng. Smart Devices, vol. 2 , no. 2 , pp. 1-18, 2015.

[24] K. Dery, I. M. Sebastian, and N. van der Meulen, "The Digital Workplace is Key to Digital Innovation," MIS Q. Exec., vol. 16, no. 2, pp. 135-152, 2017.

[25] S. L. Vargo and R. F. Lusch, "Service-Dominant Logic: Axioms of Service-Dominant Logic," 2016.

[26] W. A. Z. Wan Ahmad, M. Mukhtar, and Y. Yahya, "Validating the Contents of a Social Content Management Framework," in The 2017 6th International Conference on Electrical Engineering and Informatics (ICEEI), 2017.

[27] E. S. Alias, M. Mukhtar, and R. Jenal, "Embedding Key User Values for the Adoption of Unified Communication and Collaboration Service," in The 2017 6th International Conference on Electrical Engineering and Informatics (ICEEI), 2017.

[28] T. Borangiu and F. Polese, "Introduction to the Special Issue on Exploring Service Science for Data-Driven Service Design and Innovation Introduction to the Special Issue on Exploring Service Science for Data-Driven Service Design and Innovation," Serv. Sci., vol. 9, no. 4, 2017.

[29] S. L. Vargo and R. F. Lusch, "Service-dominant logic 2025," Int. J. Res. Mark., vol. 34, no. 1, pp. 46-67, 2017.

[30] S. L. Vargo and R. F. Lusch, "Institutions and Axioms: An Extension and Update of Service-Dominant Logic," J. Acad. Mark. Sci., pp. 1-19, 2015.

[31] C. R. Greer, R. F. Lusch, and S. L. Vargo, "A service perspective," Organ. Dyn., vol. 45, no. 1, pp. 28-38, 2016.

[32] J. D. Chandler and R. F. Lusch, "Service Systems: A Broadened Framework and Research Agenda on Value Propositions, Engagement, and Service Experience," J. Serv. Res., vol. 18, no. 1, pp. 6-22, 2015. 